\title{
Indonesia's Local Material Effect in Clay-Based Ceramic Filter Fabrication as an Alternative for Liquid Radioactive Waste Processing Material
}

\author{
Widya Rosita*, Ferdiansjah, Antonius Wisnu Yogha Pamungkas, Tri Joko Prihatin \\ Department of Engineering Physics, Universitas Gadjah Mada, Yogyakarta, Indonesia \\ Email: *widyar@ugm.ac.id
}

Received 13 June 2016; accepted 24 July 2016; published 27 July 2016

Copyright (C) 2016 by authors and Scientific Research Publishing Inc.

This work is licensed under the Creative Commons Attribution International License (CC BY). http://creativecommons.org/licenses/by/4.0/

c) (i) Open Access

\begin{abstract}
One of the procedures to handle liquid radioactive waste is by filtration process. To do this process, suitable filter should be used because of radioactive nature of the waste. Ceramic filter is one of the suitable filters that could be used for this purpose. This paper will discuss about producing ceramic filter from local clay and test its performance. Performance of the filter is given by its flux, compressive strength, Decontamination Factor (DF) and adsorption efficiency. The results show that there are almost no effects of casting pressure on both flux and compressive strength of ceramic filter, but zeolite addition produces different effect. The higher concentration of zeolite will decrease the filter flux and increase filter compressive strength. The optimal composition from this research is $70 \% \mathrm{w} / \mathrm{o}$ clay- $25 \% \mathrm{w} / \mathrm{o}$ zeolite $-5 \% \mathrm{w} / \mathrm{o}$ charcoal. It has adsorption efficiency (60.36) and Decontamination Factor (2.52). Besides, $\mathrm{Sr}$ concentration after filtration is still higher than environmental standard for $\mathrm{Sr}-90$ and more studies are still needed.
\end{abstract}

\section{Keywords}

Local Clay, Zeolite, Charcoal, Filter, Radioactive Waste

\section{Introduction}

Liquid radioactive wastes vary in solution composition and the radionuclide they contain. They came from spent

"Corresponding author.

How to cite this paper: Rosita, W., Ferdiansjah, Pamungkas, A.W.Y. and Prihatin, T.J. (2016) Indonesia's Local Material Effect in Clay-Based Ceramic Filter Fabrication as an Alternative for Liquid Radioactive Waste Processing Material. Materials Sciences and Applications, 7, 371-379. http://dx.doi.org/10.4236/msa.2016.77033 
fuel reprocessing, reactor coolant, drain, and laundry waste water. Liquid wastes should be treatment for radioactive material removal or volume reduction as coagulation-sedimentation, filtration, evaporation, and ion exchange [1]. Liquid radioactive waste produced from radioactive waste reprocessing must be handling seriously because it contains fission products. It is hazardous and easily disperses in environment. Filtration adopted by a solid filter media belongs to a solid-liquid separation process which separates the liquid components and insoluble solid components from each other by allowing the original liquid waste to contact a filtering medium. Filter technologies that have been applied were Reverse Osmosis (RO) in Chalk Rivers Laboratory in Canada, ultrafiltration in Sellafield UK, RO-Ultrafiltration combination in Wolf Creek Nuclear Power Plant, nano-filtration in Bugey Nuclear Power Plant in France, and microfiltration in Chalk Rivers Laboratory in Canada [2].

For serious nuclear accident, application of Micro Electro Mechanical Systems (MEMS) inertial impactor filter has been studied. It can filtrate and collect 1 - 3 microns aerosol particles without changing filter paper because MEMS can significantly reduce the flow resistance in filtering process. This technique uses particle inertia for separating and collecting, so based on this effect, MEMS inertial impactor model's geometry is designed into a T tube with flat nozzle inlet and entrance width is far less than its length [3].

Ceramic is available for wide application such as filter, membrane catalytic substrate and structural panel. They have low thermal expansion and thermal conductivity, high permeability and chemical inertness. Ceramic made from several materials include silicon carbide, alumina, glasses, cordierite as well as solid waste [4]. Some membrane technologies for liquid radioactive waste were developed such as polymer composites membrane and ceramic membrane in Poland. The ceramic membrane, made of titania and zirconia, has been tested and showed that it had to be combined with chelation, chemical complexation or sorption on seeds if applied to removal radioactive as small ions [5]. As a filter, ceramic from the mixture of 85.00 mass \% zeolite, 8.00 mass \% bentonite, 6.00 - 6.5 mass \% kaolinite and 0.50 - 1.00 mass \% charcoal powder had been studied. It showed uniform pore size of $0.3 \mu \mathrm{m}$ [6]. Sludge ashes, alone or mixed with kaolin, montmorillonite, Illitic clay, powdered flat glass could be used as ceramic filter material. During thermal treatment, densification and compressive strength were increased at the same time. Magnitude went to a maximum value and then diminished by over burning of material [7].

Ceramic water filter could be manufactured from local clay and sawdust. This filter was low cost but efficient for treatment drinking water in developing country. But most of available ceramic filters were not produced to treat heavy metal like zinc, nickel, manganese, lead, chromium and copper. So calcium silicate can mixed in its forming step and will act like tobermorite, to trap and absorb heavy metal in its pore [8]. In addition to conventional ceramic water filter, Magnetic Porous Ceramsite (MPC) as a Biological Aerated Filter (BAF) in wastewater treatment was investigated. It was made from goethite, sawdust and palygorskite clay mixture with mass ratio 10:2:5 and sintered at $700^{\circ} \mathrm{C}$ for 120 minutes. The result showed that this MPC had porosity $78 \%$ and compressive strength 53 - $67 \mathrm{~N}$ which was superior to the regulatory level in The Chinese National Standard [9].

Except for filtration, porous medium was also used for Magnetohydrodynamic (MHD) application. MHD is a combination between magneto (magnetic), hydro (liquid) and dynamic (movement of particles) in which magnetic field induces current flows in a dynamic fluid and creates forces on the fluid. There is a wide application of MHD through a porous channel such as diffusion technology, transpiration cooling, hemodialysis processes, and flow control in nuclear reactor. Some research shows that volume fraction of nanoparticles has affected MHD stagnation point flow, heat and mass transfer as well as entropy generation [10] [11].

Heat and mass transfer through porous medium also has a great interest in many researchers in past decades. Implementing porous media such as metal foam in compact electronic cooling became popular due to their high heat transfer area per unit volume, energy absorbent, high temperature tolerance as well as high mechanical strength. Mohammadian et al. [12] had investigated thermal management pack design for high power lithiumion battery. They used embedded aluminum metal foam inside the air flow channel to identify optimum length of inserted metal foam for decreasing standard deviation of temperature field (SDT) and maximum temperature $\left(T_{\max }\right)$ inside the battery. The result shows that compared to no porous inserted material, embedding aluminum metal foam significantly improves thermal management of Li-ion battery cell and decreasing porosity of porous will decrease SDT and $T_{\max }$. [12].

The fluid flows in porous medium are important applications in engineering such as filtration and purification process. Equation of fluid flows inside channel in porous medium is a set of non-linear Differential Equation. Homotopy Pertubation Method (HPM) is one of the novel methods for solving non-linear differential equation which is used by various researchers. Seyf and Mousevi [13] developed approximate models that provided ve- 
locity profiles and pressure distribution in channel with or without porous media with arbitrary combination of injection and suction in both stationary and moving walls. They used geometric configuration of rectangular porous channel with various boundary condition at walls. Shirazpour et al. [14] presented an analytical solution using HPM for fully developed flow in porous saturated channel subjected to Lorentz force for both coquette and Poiseuille flows. Besides, for solving non-linear differential equation, Homotopy Analitical Method (HAM) and Spectral Homotopy Analysis Method (SHAM) were also used. The advantage of SHAM is more efficient technique and does not depend on the rule of solution expression and the rule of ergodicity like HAM. Rassoulinejad-Mousavi and Abbasbandy [15] used SHAM to elucidate the initial and boundary-friction effects at the boundaries at the influential parameters (Da, M and F). All research had concluded that decreasing the value of Darcy number (Da) decreased the velocity maxima and flattened the velocity profile. Small Da values are associated with higher fluid resistance as well as lower permeability. It means that reduction of permeability of porous medium leads to decreasing fluid velocity through the channel [13]-[15].

Indonesia has abundant amount of ceramic's raw material like local clay and zeolite. Zeolite is also known as an absorbent. It has good capability and selectivity as well as low cost. Zeolite's selectivity resulted from their structure: aluminosilicate framework, exchangeable cations and zeolitic water. The aluminosilicate framework will define the crystalline structure. These crystalline structures are important in their sorption capability due to dimensions and locations of the channels through which molecule diffuses into the inter-crystalline free volume. Natural zeolites are also considered for radioactive waste treatment due to their high cation-exchange capacities and selectivity for Cs, Ba and Sr [16]. In this research, filter materials are prepared using local clay, local natural zeolite and charcoal powder as the raw material. Local clay will be ceramic's based material, zeolite will serve as ceramic's based material and also as an $\mathrm{Sr}$ adsorbent. Another material is charcoal powder that acts as the pore forming agent in the mixture. Pore-maker material will affect amount of pore that can be formed inside the filter. Therefore it will affect sieving capabilities and liquid flow rate through filter. Casting pressure plays an important role in producing denser filter, and it is expected that denser filter will have more mechanical strength. The influences of clay-zeolite-charcoal composition and casting pressure are investigated. The aim of the research is to find an optimal composition of clay-zeolite-charcoal and casting pressure that not only have high mechanical strength and good capability for adsorbing Sr component, but also have high flux that flows through it.

\section{Experimental}

\subsection{Material Preparation}

Ceramic filter material that was used in this research were clay from Godean (western part of Yogyakarta city), zeolite from Gunung Kidul (southern part of Yogyakarta city) and charcoal powder made from kesambi wood (Schleichera oleosa). Clay consists of $\mathrm{Si} 24.8 \% \mathrm{w} / \mathrm{o}, \mathrm{Al} 10.71 \% \mathrm{w} / \mathrm{o}$ and $\mathrm{Mg} 0.136 \% \mathrm{w} / \mathrm{o}$, was used as ceramic base material. It has molecular formula $\mathrm{Al}_{2} \mathrm{O}_{3} \cdot 2 \mathrm{SiO}_{2} \cdot 2 \mathrm{H}_{2} \mathrm{O}$. Charcoal contains $85 \%$ - 98\% w/o carbon. Charcoalin ceramic composition was used as pore maker. During thermal decomposition, charcoal powder was removed into carbon monoxides and carbon dioxide gases. After thermal decomposition process, the pores were created in the material [6]

The preparations of clay, charcoal and zeolite were done separately. Clay was sliced into chips and dried. The dried clay then ground and reheated in oven with temperature $50^{\circ} \mathrm{C}$ to avoid granulation during sieving. Zeolite was ground, sifts using 200 mesh sieve and activated chemically using HF 1\% solution, then neutralized and dried using oven. Charcoal was dried, ground and sifts using 200 meshsieve. Table 1 showed characterization of zeolite using Atomic Absorption Spectrophotometer.

Ceramic filter was produced by mixing zeolite-charcoal and clay. There were four different weight compositions with the variations in the amount of charcoal-zeolite. The composition was(in \% w/o) clay 70\%-zeolite $0 \%$-charcoal $30 \%$, clay $70 \%$-zeolite $5 \%$-charcoal $25 \%$, clay $70 \%$-zeolite $10 \%$-charcoal $20 \%$, clay $70 \%$-zeolite $20 \%$-charcoal $10 \%$, clay $70 \%$-zeolite $25 \%$-charcoal $5 \%$.

Each composition was pressed with casting pressing variations: $5.73 \mathrm{MPa}, 7.01 \mathrm{MPa}$, 8.28 MPa and 9.55 MPa. After casting, filter was air dried and heated in furnace until it reach $1000^{\circ} \mathrm{C}$ and was hold for 4 hours then it was cooled inside furnace to room temperature. Flux testing using water and pressure testing were done to ceramic filter. The optimal composition result from these tests then soaked in $\operatorname{Sr}\left(\mathrm{NO}_{3}\right)_{2}$ solution to simulate liquid waste that contains radioactive Sr-90 for radioactive filtering capacity test. 
Table 1. Zeolite compositions.

\begin{tabular}{cc}
\hline Components & Compositions (\%) \\
$\mathrm{SiO}_{2}$ & $64.74-66.59$ \\
$\mathrm{Al}_{2} \mathrm{O}_{3}$ & $13.89-14.17$ \\
$\mathrm{CaO}$ & $1.64-2.81$ \\
$\mathrm{Fe}_{2} \mathrm{O}_{3}$ & $0.96-1.64$ \\
$\mathrm{MgO}$ & $0.60-0.94$ \\
$\mathrm{Na}_{2} \mathrm{O}$ & $1.23-1.47$ \\
$\mathrm{~K}_{2} \mathrm{O}$ & $0.95-1.27$ \\
$\mathrm{MnO}$ & $0.16-0.18$ \\
$\mathrm{H}_{2} \mathrm{O}$ & $2.22-2.61$ \\
\hline
\end{tabular}

\subsection{Sample Characterization}

The parameters in this research are flux, porosity percentage, compressive strength, Decontamination Factor (DF) and adsorption efficiency.

Flux $(J)$ was determined using the following formula

$$
J=V /(A \cdot t)
$$

where $V$ is volume of solution, $A$ is surface area and $t$ is flowing time.

Compressive strength $(\sigma)$ is formulated as

$$
\sigma=F / A
$$

where $F$ is force and $A$ is surface area

Porosity percentage, $\% P$ is known by its water adsorption power, and was measured using formula as

$$
\% P=\left[\left(m_{b}-m_{k}\right) / \rho_{\text {water }} \cdot V_{t}\right] \times 100 \%
$$

where $m_{b}=$ weight of wet sample, $m_{k}=$ weight of dry sample

Decontamination factor (DF) is ratio between pre-treatment liquid waste activity $\left(A_{0}\right)$ and post-treatment one $\left(A_{F}\right)$. Post-treatment activity means that liquid activity after being processed.

$$
F D=A_{0} / A_{F}
$$

\section{Result and Discussion}

\subsection{Flux Test Result}

Table 2 and Figure 2 shows flux test result when ceramic filter was used to filter water. Besides Table 3 shows porosity percentage resulted from various casting pressure and composition.

Table 2 and Table 3 show that all mean value of flux testing and percentage porosity measurement due to casting pressure variations has almost same value. It shows that casting pressure has no effect on flux and percentage porosity but zeolite composition has. Figure 1 shows that, in all casting pressure, adding the amount of zeolite composition until $10 \%$ will increase flux, but for composition $20 \%$ and $25 \%$ will decrease the flux. Zeolite could act as a filter because its cavities, so increasing zeolite content will give more canals. But increasing zeolite composition, higher than $10 \%$, will also decrease charcoal content in filter. Charcoal powder which is mixed with the clay will burn out during heat treatment and made filter porous so water could flow through it [8]. So decreasing charcoal powder composition will make the filter denser and will decrease flux.

Filter performance, such as flux, affected by density and size of filter's pores. Organic burn-out material will combust in high temperature heating and leaving cavities in fired clay. These cavities made water flow easily through it compared to pores in clay so flow rate per area will increase [17]. We should compared Figure 2 and Figure 3 to make correlation between porosity percentage, density and flux in this research. From Figure 3, we 
Table 2. Effect of casting pressure and composition of mixture to flux.

\begin{tabular}{cccccc}
\hline \multirow{2}{*}{$\begin{array}{c}\text { Casting Pressure } \\
(\mathrm{MPa})\end{array}$} & \multicolumn{5}{c}{ Flux (L/m².jam) } \\
\cline { 2 - 6 } & $\begin{array}{c}\text { Zeolite } \\
\text { 0\%-Charcoal 30\% }\end{array}$ & $\begin{array}{c}\text { Zeolite } \\
\text { 5\%-Charcoal 25\% }\end{array}$ & $\begin{array}{c}\text { Zeolite } \\
\text { 10\%-charcoal 20\% }\end{array}$ & $\begin{array}{c}\text { Zeolite } \\
\text { 20\%-charcoal 10\% }\end{array}$ & $\begin{array}{c}\text { Zeolite } \\
25 \% \text {-Charcoal 5\% }\end{array}$ \\
\hline 5.73 & $8.24 \pm 0.19$ & $14.91 \pm 0.11$ & $14.37 \pm 0.16$ & $6.36 \pm 0.13$ & $6.61 \pm 0.26$ \\
7.01 & $7.22 \pm 0.00$ & $21.82 \pm 1.38$ & $15.58 \pm 0.02$ & $5.83 \pm 0.48$ & $8.23 \pm 0.13$ \\
8.28 & $8.34 \pm 0.00$ & $20.13 \pm 0.91$ & $16.71 \pm 0.20$ & $7.07 \pm 0.85$ & $6.22 \pm 0.30$ \\
9.55 & $6.89 \pm 0.02$ & $14.57 \pm 0.16$ & $15.27 \pm 0.69$ & $5.80 \pm 0.28$ & $6.10 \pm 0.05$ \\
\hline
\end{tabular}

Table 3. Effect of casting pressure and composition of mixture to percentage porosity.

\begin{tabular}{|c|c|c|c|c|c|}
\hline \multirow{2}{*}{$\begin{array}{l}\text { Casting Pressure } \\
(\mathrm{MPa})\end{array}$} & \multicolumn{5}{|c|}{ Porosity (\%) } \\
\hline & $\begin{array}{c}\text { Zeolite } \\
\text { 0\%-Charcoal 30\% }\end{array}$ & $\begin{array}{c}\text { Zeolite } \\
\text { 5\%-Charcoal 25\% }\end{array}$ & $\begin{array}{c}\text { Zeolite } \\
10 \% \text {-charcoal 20\% }\end{array}$ & $\begin{array}{c}\text { Zeolite } \\
\text { 20\%-charcoal 10\% }\end{array}$ & $\begin{array}{c}\text { Zeolite } \\
\text { 25\%-Charcoal 5\% }\end{array}$ \\
\hline 5.73 & $40.59 \pm 1.22$ & $49.04 \pm 0.10$ & $41.48 \pm 1.38$ & $38.13 \pm 0.11$ & $30.41 \pm 0.13$ \\
\hline 7.01 & $42.41 \pm 0.05$ & $46.56 \pm 0.13$ & $43.31 \pm 0.14$ & $37.78 \pm 0.15$ & $35.42 \pm 0.87$ \\
\hline 8.28 & $42.99 \pm 0.36$ & $49.98 \pm 0.29$ & $48.27 \pm 0.96$ & $37.25 \pm 0.50$ & $31.66 \pm 1.58$ \\
\hline 9.55 & $39.99 \pm 0.99$ & $47.77 \pm 0.04$ & $45.60 \pm 0.46$ & $39.55 \pm 1.77$ & $29.92 \pm 0.79$ \\
\hline
\end{tabular}

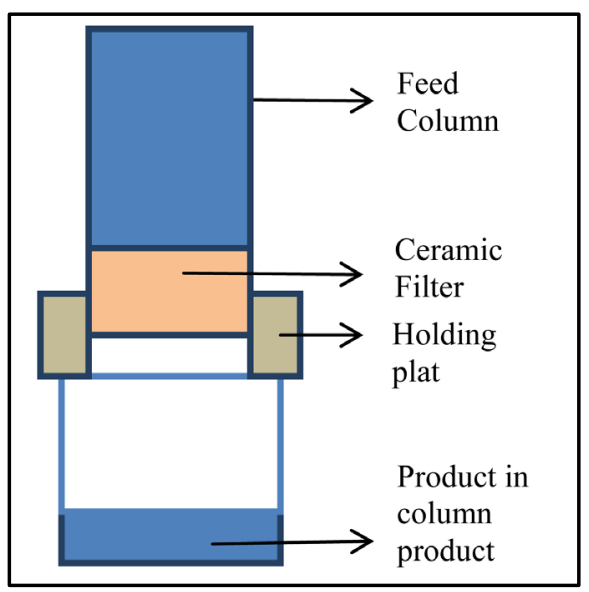

Figure 1. Experimental schematic of filtration.

know that casting pressure variation has no effect on porosity but zeolite content in filter composition has. When zeolite content is increased and the charcoal powder as a pore-maker decreased. At high temperature, charcoal powder is burned into gas and made porous material, so if proportion of charcoal powder decreased, the percent of porosity would decrease [6]. A similar research by Bao et al. ([9] using sawdust as a pore maker, showed that when sawdust content was increased from 0 to $20 \mathrm{wt} \%$, it made porosity increased from $67 \%$ to $90 \%$.

Porosity decrease means filter will have small pores. In pores perspectives, small pores size increases friction between fluid and porous structure, so permeability of porous medium will decrease and lead to increasing pressure drop along the channel. Lower permeability of porous material due to decreasing in Darcy number, prevents penetrating of the fluid therefore less amount of flow enters the channel and lower velocity is attained [13]-[15]. Increasing zeolite content and decreasing charcoal powder content will decrease Darcy number so the permeability of filter will decrease and flux become slower.

\subsection{Compressive Strength Test Result}

Table 4 and Figure 4 show that zeolite composition has significant effect to compressive strength but not the 


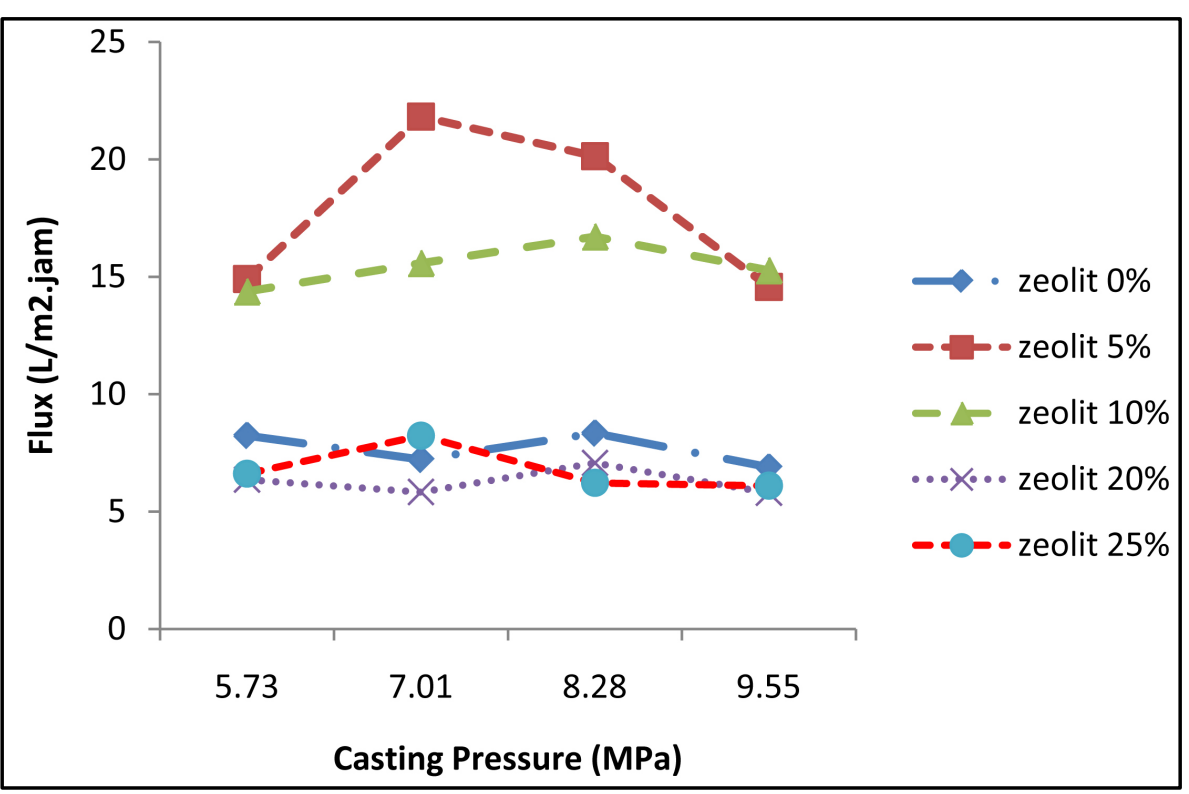

Figure 2. Casting pressure effect to filter flux in various zeolite-charcoal composition.

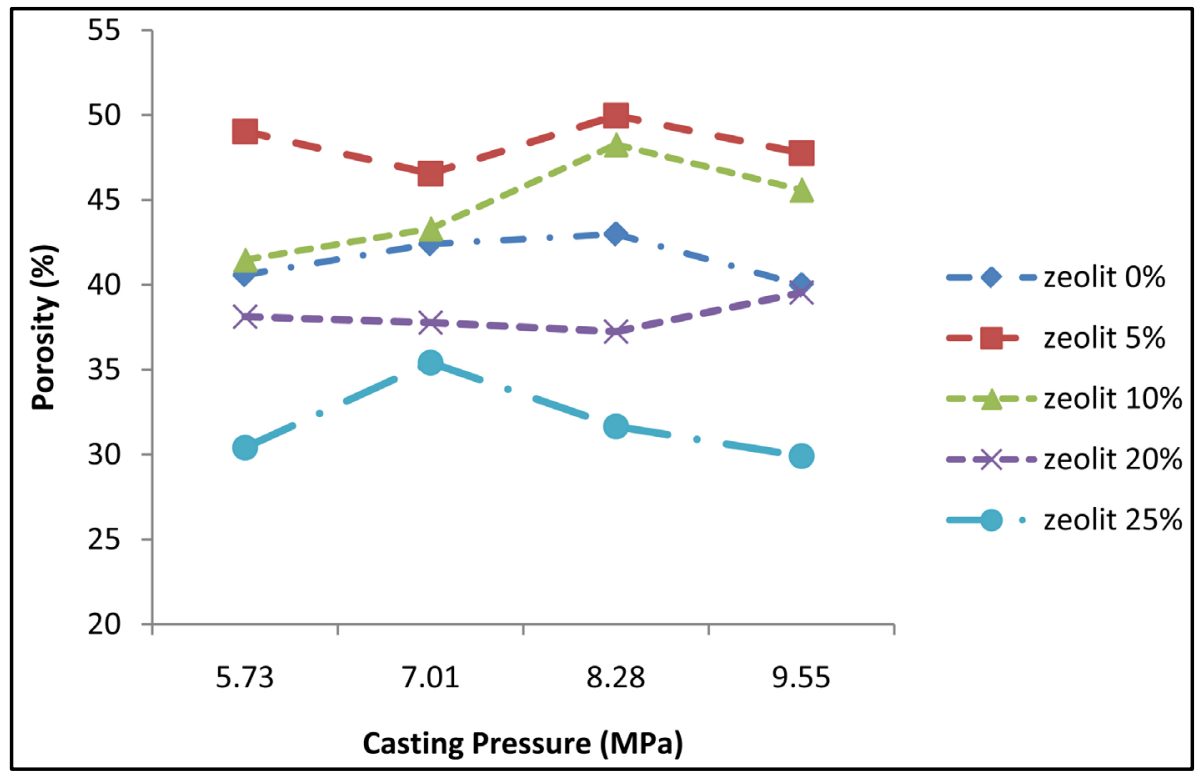

Figure 3. Casting pressure effect to filter porosity in various zeolite-charcoal composition.

casting pressure.

Increasing zeolite composition will increase compressive strength. Zeolite has a $\mathrm{SiO}_{4}$ or $\mathrm{AlO}_{4}$ tetrahedral structure with cages and cavities as secondary structures due to different arrangement of tetrahedral structures [18], but charcoal has amorphous structure. Filter will have higher strength if it has structure rather than amorphous form so reducing charcoal content will reduce amorphous form. Besides, charcoal is a pore-maker and hence the porosity of the final product depends on charcoal powder content [19]. This result also similar with result's research by Bao et al. [9], when sawdust content was increased, compressive strength of MPC will decreased from 59 to $45 \mathrm{~N}$. It conclude that show dust could react with Carbon to produce $\mathrm{CO}_{2}$. $\mathrm{CO}_{2} \mathrm{product}$ could expand or diffuse through channel inside MPC so will reduce compressive strength of MPC.

The less pores will make filter stronger. From Figure 4, we can conclude that filter with $25 \%$ zeolite has higher compressive strength. 


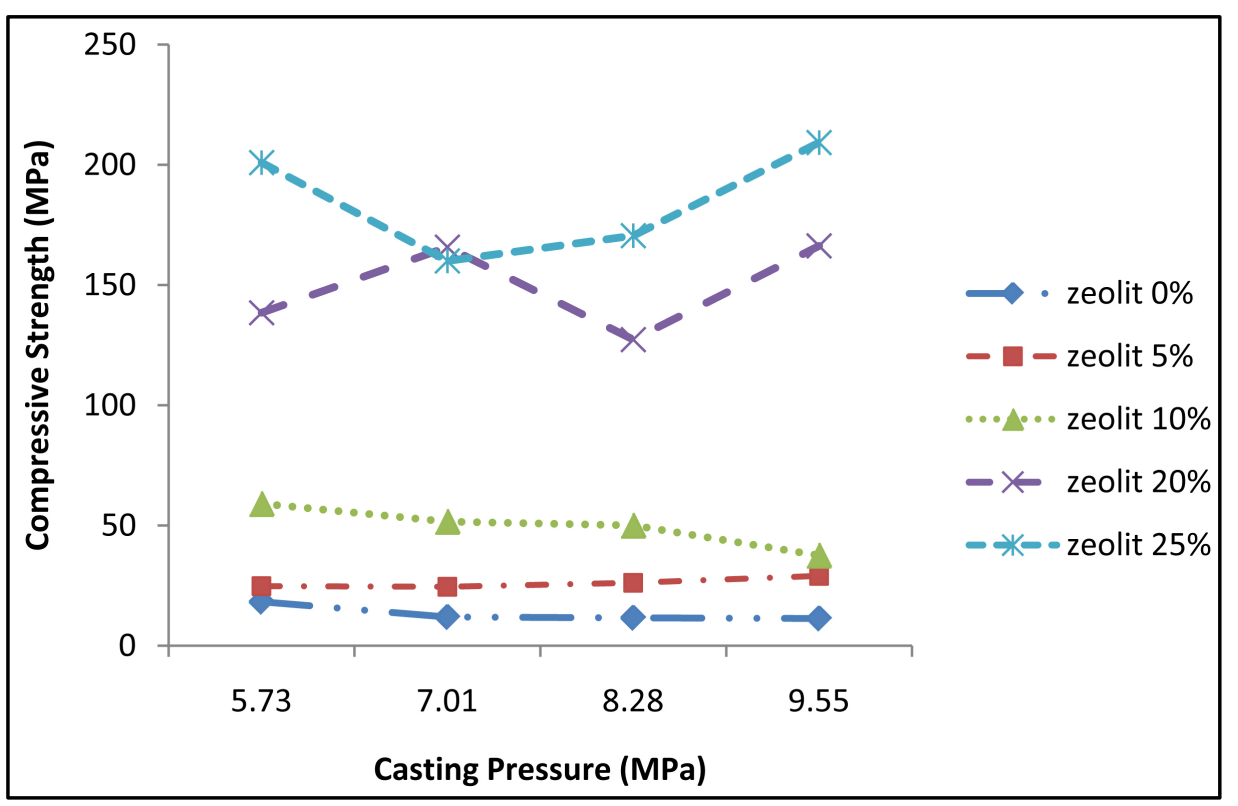

Figure 4. Casting pressure effect to compressive strength in various zeolite composition.

Table 4. Effect of casting pressure and composition of mixture to compressive strength.

\begin{tabular}{cccccc}
\hline \multirow{2}{*}{$\begin{array}{c}\text { Casting Pressure } \\
\text { (MPa) }\end{array}$} & \multicolumn{4}{c}{ Compressive Strength (MPa) } \\
\cline { 2 - 6 } & Zeolite & $\begin{array}{c}\text { Zeolite } \\
\text { 0\%-Charcoal 30\% }\end{array}$ & $\begin{array}{c}\text { Zeolite } \\
\text { 5\%-Charcoal 25\% }\end{array}$ & $\begin{array}{c}\text { 10\%-charcoal 20\% } \\
\text { 20\%-charcoal 10\% }\end{array}$ & \begin{tabular}{c} 
25\%-Charcoal 5\% \\
\hline 5.73
\end{tabular} \\
$18.30 \pm 1.32$ & $24.78 \pm 0.14$ & $59.07 \pm 5.91$ & $138.45 \pm 42.50$ & $200.91 \pm 11.42$ \\
7.01 & $11.93 \pm 2.58$ & $24.53 \pm 0.80$ & $51.65 \pm 7.27$ & $165.82 \pm 6.81$ & $160.00 \pm 4.37$ \\
8.28 & $11.61 \pm 0.03$ & $26.16 \pm 3.92$ & $50.05 \pm 9.10$ & $127.28 \pm 22.57$ & $170.53 \pm 10.14$ \\
9.55 & $11.33 \pm 0.52$ & $29.03 \pm 1.10$ & $37.60 \pm 5.92$ & $166.3 \pm 0.38$ & $209.27 \pm 44.40$ \\
\hline
\end{tabular}

\subsection{Radioactive Filtering Capacity Test}

Flux test result shows that filter with $25 \%$ w/o zeolite content, which is formed using $7.01 \mathrm{MPa}$ casting pressure, has good enough flux capability. It also has the lowest porosity value. Compressive strength shows that filter with $25 \%$ w/o zeolite content has the highest value. For radioactive filtering capacity test, we use the optimal value of filter composition forming. The filter composition optimal value is based on flux value and compressive strength value. Filter should have high compressive strength but also the fluid can easily passes through it. So the optimal composition result from flux test and compressive strength test is clay $70 \%$-zeolite $25 \%$ and charcoal 5\%. Then filter formed using this composition is soaked in $\mathrm{Sr}-90$ waste simulation using $\operatorname{Sr}\left(\mathrm{NO}_{3}\right)_{2}$ solution for filtering capacity test. The initial concentration of Sr solution is $65 \mathrm{ppm}$. The radioactive filtering capacity test result shown is Table 5 .

This filter made from $70 \%$ w/o clay-25\% w/o zeolite-5\% w/o charcoal shows the value of adsorption efficiency is 60.36 and Decontamination Factor (FD) is 2.52. The FD value resulted from this filter is lower than FD ultrafiltration using Polyethersulfone (PES), Polysulfone (PS) and Surface Modified (SMM) Membranes which have value between 35 - 230 [20]. It means 5\% zeolite was not enough for increasing FD although zeolite has adsorption and ion exchanger capabilities. Sorption capacity was affected by Si/Al ratio as well as pore size. Zeolite with low Si/Al ratio, will have high sorption capacities because they have more binding site. Acid activation using strong acid will break $\mathrm{Al}$ bonding so zeolite will have low $\mathrm{Si} / \mathrm{Al}$ ratio [18]. This research used HF for zeolite activation so we will have zeolite with low Si/Al ratio and only adsorb low amount of $\mathrm{Sr}$ atom. Meanwhile, active site where atom could be bonded was also present inside pores so pore size plays an important function for adsorb the atom. Atom/ion size that is larger than pore size can be retarded [21]. This research 
Table 5. The radioactive filtering capacity test result.

\begin{tabular}{ccccc}
\hline Filter made from & $\begin{array}{c}\text { Sr concentration } \\
(\mathrm{ppm}) \text { before filtration } \\
\text { process }\end{array}$ & $\begin{array}{c}\text { Sr concentration } \\
(\mathrm{ppm}) \text { after filtration } \\
\text { process }\end{array}$ & $\begin{array}{c}\text { Adsorption } \\
\text { efficiency } \\
(\%)\end{array}$ & $\begin{array}{c}\text { Decontamination } \\
\text { Factor }\end{array}$ \\
\hline $\begin{array}{c}70 \% \text { w/o clay-25\% w/o zeolite-5\% w/o } \\
\text { charcoal }\end{array}$ & 65 & 25.77 & 60.36 & 2.52 \\
\hline
\end{tabular}

did not measure filter pore size but Mopoung et al. [6] said that filter made from $85 \%$ mass zeolite, $8 \%$ mass bentonite, $6 \%$ - 6.5\% kaolinite and $0.5 \%$ - $1 \%$ charcoal powder had uniform pore size $0.3 \mu \mathrm{m}$. This pore size is still bigger than in ultrafiltration, that have 0.001 and $0.1 \mu \mathrm{m}$ pore size. It means ultrafiltration will have better sorption capacity.

The Sr concentration after filtration is $25.77 \mathrm{ppm}$ which is equal to $3.54 \mathrm{Ci} / \mathrm{l}\left(1.3 \times 10^{11} \mathrm{~Bq} / \mathrm{l}\right)$. This value is still higher than environmental standard for Sr-90 $\left(4 \times 10^{3} \mathrm{~Bq} / \mathrm{l}\right)$ [22] so we need multiple filtrations or combination with other separation process to make effluent concentration meet the environmental standard value.

\section{Conclusions}

The research explores local material which is potential as ceramic filter to handle liquid radioactive waste. The research aim is to find an optimal composition of local clay-zeolite-charcoal and casting pressure that have high mechanical strength and good capability for adsorbing Sr component but also have high flux that flows through it. Ceramic filter was made from Clay from Godean, Zeolite from Gunung Kidul and Kesambi Charcoal powder with various mixed composition and casting pressure.

The results show that there are almost no effects of casting pressure on both flux and compressive strength of ceramic filter, but zeolite addition has. The higher concentration of zeolite will decrease the filter flux and increase filter compressive strength. The optimal composition from this research is $70 \% \mathrm{w} / \mathrm{o}$ clay- $25 \% \mathrm{w} / \mathrm{o}$ zeolite-5\% w/o charcoal. It has adsorption efficiency (60.36) and Decontamination Factor (2.52). Besides, Sr concentration after filtration is still higher than environmental standard for Sr-90 and more studies are still needed.

In addition to liquid radioactive waste treatment purposes, ceramic filter produced from this research is also potential for drinking water treatment, but more studies in this purpose are still needed.

\section{Acknowledgements}

The authors gratefully acknowledge the support of the Department of Nuclear Engineering and Engineering Physics, Universitas Gadjah Mada.

\section{References}

[1] Nagasaki, S. and Nakayama, S. (2011) Radioactive Waste Engineering and Management. Springer, Tokyo.

[2] Zakrzewska-Trznadel, G. (2013) Advances in Membrane Technologies for the Treatment of Liquid Radioactive Waste. Desalination, 321, 119-130. http://dx.doi.org/10.1016/j.desal.2013.02.022

[3] Niu, F.L., Du, X.C., Qi, H.C., Yi, M.Q. and Yang, X. (2016) Modeling Analyses of Radioactive Aerosol Flow and Collection in Mesoscopic Impactor Filters. Progress in Nuclear Energy, 88, 147-155. http://dx.doi.org/10.1016/j.pnucene.2015.12.010

[4] Carvalho, A.C., Raupp-Pereira, F., Neto, J.B.R. and de Olivera, A.P.N. (2015) A New Source for Production of Ceramic Filters. Materials Letters, 145, 250-252. http://dx.doi.org/10.1016/j.matlet.2015.01.131

[5] Zakrzewska-Trznadel, G. and Harasimowicz, M. (2004) Application of Ceramic Membranes for Hazardous Wastes Processing: Pilot Plant Experiments with Radioactive Solutions. Desalination, 162, 191-199. http://dx.doi.org/10.1016/S0011-9164(04)00042-6

[6] Mopoung, S., Sriprang, N. and Namahoot, J. (2014) Sintered Filter Materials with Controlled Porosity for Water Purification Prepared from Mixtures with Optimal Ratio of Zeolite, Bentonite, Kaolinite, and Charcoal. Applied Clay Science, 88-89, 123-128. http://dx.doi.org/10.1016/j.clay.2013.11.035

[7] Merino, L., Arivato, L.F. and Romero, F. (2007) Preparation and Characterization of Ceramic Products by Treatment of Sewage Sludge Ashes Mixed with Different Additives. Waste Management, 27, 1829-1844. http://dx.doi.org/10.1016/j.wasman.2006.10.008 
[8] Ajayi, B.A. and Lamidi, Y.D. (2015) Formulation of Ceramic Water Filter Composition for the Treatment of Heavy Metals and Correction of Physiochemical Parameters in Household Water. Art and Design Review, 3, 94-100. http://dx.doi.org/10.4236/adr.2015.34013

[9] Bao, T., Chen, T., Liu, H., Chen, D., Qing, C. and Frost, R.L. (2014) Preparation of Magnetic Porous Ceramsite and Its Application in Biological Aerated Filters. Journal of Water Process Engineering, 4, 185-195. http://dx.doi.org/10.1016/j.jwpe.2014.10.004

[10] Mabood, F., Shateyi, S., Rashidi, M.M., Momoniat, E. and Freidoonimehr, N. (2016) MHD Stagnation Point Flow Heat and Mass Transfer of Nanofluids in Porous Medium with Radiation, Viscous Dissipation and Chemical Reaction. Advanced Powder Technology, 27, 742-749. http://dx.doi.org/10.1016/j.apt.2016.02.033

[11] Ibanez, G., Lopez, A., Pantoja, J. and Moreira, J. (2016) Entropy Generation Analysis of Nanofluid Flow in MHD Porous Microchannel with Hydrodynamic Slip and Thermal Radiation. International Journal of Heat and Mass Transfer, 100, 89-97. http://dx.doi.org/10.1016/j.ijheatmasstransfer.2016.04.089

[12] Mohammadian, S.K., Rassoulinejad-Mousavi, S.M. and Zhang, Y.W. (2015) Thermal Management Improvement of an Air-Cooled High-Power Lithium-Ion Battery by Embedding Metal Foam. Journal of Power Sources, 296, 305-313. http://dx.doi.org/10.1016/j.jpowsour.2015.07.056

[13] Seyf, H.R. and Rassoulinejad-Mousavi, S.M. (2011) An Analytical Study for Fluid Flow in Porous Media Imbedded inside a Channel with Moving or Stationary Walls Subjected to Injection/Suction. Journal of Fluid Engineering, 133, Article ID: 091203.

[14] Shirazpour, A., Rassoulinejad-Mousavi, S.M. and Seyf, H.R. (2011) HPM Solution of Momentum Equation for DarcyBrinkman Model in Parallel Plates Channel Subjected to Lorentz Force. International Journal of Mechanical, Aerospaces, Mechatronic and Manufacturing Engineering, 5, 258-262.

[15] Rassoulinejad-Mousavi, S.M. and Abbasbandy, S. (2011) Analysis of Forced Convection in a Circular Tube Filled with a Darcy-Brinkman-Forchheimer Porous Medium Using Spectral Homotopy Analysis Method. Journal of Fluids Engineering, 133, Article ID: 101207. http://dx.doi.org/10.1115/1.4004998

[16] Borai, E.H., Harjula, R., Malinen, L. and Paajanen, A. (2009) Efficient Removal of Cesium From Low Level Radioactive Liquid Waste Using Natural and Impregnated Zeolites Minerals. Journal of Hazardous Material, 172, 416-422. http://dx.doi.org/10.1016/j.jhazmat.2009.07.033

[17] Hagan, J.M., Harley, N., Hughes, R., Pointing, D., Sampson, M., Soam, V. and Smith, K. (2009) Ceramic Water Filter Handbook. Resource Development International-Cambodia, Phnom Penh.

[18] Ziyath, A.M., Mahbub, P., Goonetilleke, A., Adebajo, M.O., Kokot, S. and Oloyede, A.(2011) Influence of Physical and Chemical Parameters on the Treatment of Heavy Metals in Polluted Stormwater Using Zeolite-A Review. Journal of Water Resource and Protection, 3, 758-767. http://dx.doi.org/10.4236/jwarp.2011.310086

[19] Zhang, F., Qi, C.X., Wang, S., Liu, J. and Cao, H. (2011) A Study on Preparation of Cordierite Gradient Pores Porous Ceramics from Rectorite. Solid State Sciences, 13, 929-933. http://dx.doi.org/10.1016/j.solidstatesciences.2011.02.015

[20] Khaeti, M., Harasimowicz, M., Jaworska, A. and Trznadel, G.Z. (2008) Removal of Radionuclides from Water Solution in Ultrafiltration/Complexation Prosess with Polyethersulfone (Pes), Polysulfone (Ps) and Surface-Modified (Smm) Membranes. XXIII ARS Separatoria, Toruń, 369-372.

[21] Hui, K.S., Chao, C.Y.H. and Kot, S.C. (2005) Removal of Mixed Heavy Metal Ions in Wastewater by Zeolite 4A and Residual Products from Recycled Coal Fly Ash. Journal of Hazardous Materials, 127, 89-101. http://dx.doi.org/10.1016/j.jhazmat.2005.06.027

[22] Director of BAPETEN Decree No 01/Ka-BAPETEN/V-99. BAPETEN. Jakarta. 


\section{Submit or recommend next manuscript to SCIRP and we will provide best service for you:}

Accepting pre-submission inquiries through Email, Facebook, LinkedIn, Twitter, etc.

A wide selection of journals (inclusive of 9 subjects, more than 200 journals)

Providing 24-hour high-quality service

User-friendly online submission system

Fair and swift peer-review system

Efficient typesetting and proofreading procedure

Display of the result of downloads and visits, as well as the number of cited articles

Maximum dissemination of your research work

Submit your manuscript at: http://papersubmission.scirp.org/ 